\title{
REFLEXIONES SOBRE EL REFORMISMO Y LA OBESIDAD CONSTITUCIONAL EN MÉxico. DE LA COSTUMBRE INSTITUCIONAL A LA REALIDAD CULTURAL
}

\section{Ramón Gil Carreón Gallegos ${ }^{1}$}

\section{Resumen}

El trabajo pretende hacer un análisis sobre las múltiples reformas a la Constitución mexicana que refleja una excesiva actividad reformista de los legisladores, así como el gran aumento del contenido de la Constitución desde su aprobación en el año de 1917. El aumento enorme de sus contenidos así como la constante reforma de la Constitución no se ha reflejado en una cultura de legalidad, al contrario, en la actualidad existe un desconocimiento general del texto constitucional mexicano, además de que existen serios problemas en el país que plantean una crisis del Estado, la Constitución y los derechos humanos. Esta breve aportación pretende mostrar que el reformismo y el aumento desmedido de los contenidos de la Constitución mexicana no son el camino adecuado para consolidar al Estado de Derecho mexicano.

Palabras clave: Reformismo, constitución mexicana, cultura constitucional, estado de derecho, rigidez constitucional.

\section{INTRODUCCIÓN}

La Constitución mexicana aprobada en el año de 1917 recientemente ha cumplido cien años, aunque bien puede sostenerse que realmente se trata de un acta de reformas de la Constitución de 1857, sin embargo, al margen de esta circunstancia en cuanto a la fecha de su génesis, el texto constitucional ha sido objeto de múltiples reformas que han modificado sustancialmente el contenido y la amplitud de la carta magna mexicana.

\footnotetext{
${ }^{1}$ Doctor con mención Cum Laude en Estudios Avanzados en Derechos Humanos por la Universidad Carlos III de Madrid, España. Profesor de la Facultad de Derecho y Ciencias Políticas y su División de Estudios de Posgrado de la Universidad Juárez del Estado de Durango e Investigador del Instituto de Investigaciones Jurídicas de la misma Universidad. México. E-mail: ramongil77@hotmail.com
} 
En teoría la Constitución mexicana tiene un diseño que la clasificaría como un texto constitucional rígido, pues el mecanismo normativo para su modificación requiere de una mayoría calificada diferente al trabajo cotidiano del legislador ordinario, sin embargo, en los hechos, esa rigidez constitucional teórica se ha convertido en una flexibilidad pura teniendo en cuenta las más de setecientas reformas de sus contenidos.

Las constantes reformas no sólo han modificado los contenidos del texto constitucional de 1917, sino que además lo han engrosado de manera preocupante casi triplicando su tamaño, haciendo de la Constitución un ordenamiento sumamente reglamentario en muchas de sus partes. Esta circunstancia ha aumentado la complejidad en la comprensión de la Constitución, sobre todo para la gran mayoría de la población, lo que aunado a otros factores sociales y culturales ha propiciado una débil cultura constitucional y de legalidad, que sin duda, incide en la preocupante crisis de la vigencia real de la Constitución mexicana.

Este trabajo desarrolla algunas líneas argumentativas sobre estos tópicos que dan cuenta del diseño constitucional mexicano, del aumento preocupante de las reformas constitucionales por periodo presidencial, del reformismo y el aumento de sus contenidos, de los datos de las encuestas de cultura constitucional y otros instrumentos que dan cuenta de la percepción de los mexicanos sobre su Constitución y otros temas relevantes, así como de algunas cifras que reflejan la grave crisis de violencia e ilegalidad que vive México.

\section{RÍGIDEZ, REFORMISMO Y OBESIDAD CONSTITUCIONAL}

En el año 2017, concretamente el 05 de febrero, se cumplieron cien años de la promulgación oficial de la Constitución mexicana. Se ha discutido si la Constitución vigente es una nueva Constitución o es una reforma de la anterior, pues de hecho en los debates del Constituyente e incluso en su promulgación se hablaba indistintamente de reformas a la Constitución de 1857 o de la Constitución de 1917. De hecho, formal y técnicamente es un acta de reformas (CPEUM).

De hecho, en su origen es difícil precisar los motivos concretos y el momento en que surge la idea de crear una nueva Constitución (CARPIZO: 1979: 59) -si es que ello fue así-, pero en todo caso, el 14 de septiembre de 1916 Carranza reformó varios artículos de su Plan de Guadalupe y convocó a un Congreso Constituyente que debía celebrar sus trabajos en la ciudad de Querétaro durante un plazo máximo de dos meses (diciembre y enero).

El maestro Jorge Carpizo expresaba en su momento que existían buenas y suficientes razones para considerarla un nuevo ordenamiento constitucional. Entre ellas, mencionaba unas de carácter procesal concernientes a la circunstancia de haber convocado a un Congreso Constituyente nacional y la inclusión de 
múltiples contenidos sociales que difieren mucho de los de la Constitución liberal antecesora (CARPIZO: 1979: 123). Pero al margen de considerar a la actual Constitución mexicana como reforma de la anterior o como un nuevo ordenamiento, lo cierto es que no puede negarse la gran similitud de ambos textos. Tanto en su estructura como en sus contenidos, dichas constituciones tienen grandes semejanzas, pero aun así, los contenidos sociales introducidos en el texto constitucional vigente marcan la gran diferencia.

Desde su origen, la Constitución vigente estableció un procedimiento de reforma constitucional que dibujaban a una Constitución rígida pues no permitía (hasta hoy en día) las modificaciones mediante procesos ordinarios. El artículo 135 que desde el año de 1917 ha tenido dos reformas estableció lo siguiente:

"Art. 135.- La presente Constitución puede ser adicionada o reformada. Para que las adiciones o reformas lleguen a ser parte de la misma, se requiere que el Congreso de la Unión, por el voto de las dos terceras partes de los individuos presentes, acuerden las reformas o adiciones, que éstas sean aprobadas por la mayoría de las legislaturas de los Estados. El Congreso de la Unión hará el cómputo de los votos de las legislaturas, y la declaración de haber sido aprobadas las adiciones o reformas." (CPEUM: 1917)

Como puede apreciarse, desde 1917 la Constitución mexicana estableció que una modificación a su texto debe ser aprobada por la mayoría calificada de las dos Cámaras que integran el Congreso de la Unión, así como por la mayoría de los parlamentos estatales.

En ese sentido, para realizar una aproximación conceptual al tema de la rigidez constitucional, Riccardo Guastini distingue cuatro tipos de Constituciones, a saber:

"1) En primer lugar, Constituciones que expresamente excluyen su modificación o reforma;

2) En segundo lugar, Constituciones que no disponen nada en torno a su modificación o reforma;

3) En tercer lugar, Constituciones que prevén un procedimiento de reforma constitucional más complejo que el procedimiento legislativo ordinario (un procedimiento "agravado", como se suele decir);

4) En cuarto lugar, Constituciones que expresamente consienten la reforma constitucional a través de el (sic) procedimiento legislativo ordinario." (GUASTINI: 2000: 175)

De tal suerte, una Constitución sería rígida no sólo por tener establecido un procedimiento agravado o más complejo para modificar sus contenidos que el previsto para modificar las leyes ordinarias, sino que además, ocuparía un sitio privilegiado en la jerarquía normativa, esto es, sería rígida en virtud de su supremacía normativa en todo el ordenamiento jurídico (GUASTINI: 2000: 178).

En el caso mexicano, el artículo 133 de la Constitución, que ha tenido dos reformas, la primera en 1934 y la segunda en el año 2016, contiene las bases para establecer el principio de jerarquía de las normas jurídicas del sistema jurídico. Este precepto actualmente establece lo siguiente:

"Artículo 133. Esta Constitución, las leyes del Congreso de la Unión que emanen de ella y todos los tratados que estén de acuerdo con la misma, celebrados y que se celebren por el Presidente de la República, con aprobación del Senado, serán la Ley Suprema de toda la Unión. Los jueces de cada entidad federativa se arreglarán a dicha Constitución, leyes y 
tratados, a pesar de las disposiciones en contrario que pueda haber en las Constituciones o leyes de las entidades federativas."

La última reforma de este artículo, publicada en el Diario Oficial de la Federación del 29 de enero del 2016, únicamente modifica la palabra "Estados" y la sustituye por "entidades federativas", quedando igual el contenido restante del precepto.

Este artículo, establece las bases jurídicas de la supremacía normativa de la Constitución, aunque deben ponderarse algunas consideraciones que se han realizado a partir de la reforma constitucional en materia de derechos humanos en el año 2011. Sobre el particular, algunos han considerado que hasta antes de dicha reforma, la relación entre el Derecho internacional y la Constitución mexicana se entendió como una relación de jerarquía, fundada en la idea de supremacía constitucional establecida por el mencionado artículo 133.

A partir de la reforma constitucional del año 2011, los primeros dos párrafos del artículo primero de la Constitución mexicana constituyen la base normativa y conceptual para la existencia de un bloque de constitucionalidad de los derechos humanos. Textualmente estos párrafos disponen:

"Artículo 1o. En los Estados Unidos Mexicanos todas las personas gozarán de los derechos humanos reconocidos en esta Constitución y en los tratados internacionales de los que el Estado Mexicano sea parte, así como de las garantías para su protección, cuyo ejercicio no podrá restringirse ni suspenderse, salvo en los casos y bajo las condiciones que esta Constitución establece.

Las normas relativas a los derechos humanos se interpretarán de conformidad con esta Constitución y con los tratados internacionales de la materia favoreciendo en todo tiempo a las personas la protección más amplia.

...." (CPEUM)

De la lectura de estos párrafos, se advierte que el primero ubica e incluye a los derechos humanos reconocidos en los tratados internacionales de los que México sea parte, a la par de los derechos humanos reconocidos en la Constitución. Este nuevo enunciado normativo constitucional ha generado una nueva realidad para el Derecho constitucional, en especial para el subsistema de los derechos humanos. Dicho párrafo hace una remisión a normas de derechos humanos contenidas en tratados internacionales reconocidos por México, pero tal remisión tiene una jerarquía constitucional, al unir y formar un solo conjunto de normas de derechos humanos contenidas en ordenamientos diversos a través de la conjunción copulativa " $y$ ".

Por su parte, el segundo párrafo del citado artículo primero de la Constitución, con la misma conjunción copulativa une y forma un solo conjunto de derechos humanos contenidos en el propio texto constitucional y en los tratados internacionales, como la fuente de interpretación o parámetro de constitucionalidad de las normas de derechos humanos, teniendo en todo momento como criterio interpretativo el principio pro persona. Por otro lado, debe puntualizarse que este segundo párrafo ubica sólo a los tratados internacionales de la materia, en el mismo plano normativo.

De tal suerte, en virtud de la reforma no sólo serían normas constitucionales las que aparecen en la 
Constitución, sino que además tendrían el mismo rango constitucional aquellas que no están dentro del texto de ésta, pero a las cuales remite expresamente, incluidos los principios, valores e interpretaciones que se hicieran, más aún si estas últimas son más favorables para la persona. En ese sentido se ha pronunciado la Suprema Corte de Justicia de la Nación al apuntar lo siguiente:

"JURISPRUDENCIA EMITIDA POR LA CORTE INTERAMERICANA DE DERECHOS HUMANOS. ES VINCULANTE PARA LOS JUECES MEXICANOS SIEMPRE QUE SEA MÁS FAVORABLE A LA PERSONA. Los criterios jurisprudenciales de la Corte Interamericana de Derechos Humanos, con independencia de que el Estado Mexicano haya sido parte en el litigio ante dicho tribunal, resultan vinculantes para los Jueces nacionales al constituir una extensión de la Convención Americana sobre Derechos Humanos, toda vez que en dichos criterios se determina el contenido de los derechos humanos establecidos en ese tratado. La fuerza vinculante de la jurisprudencia interamericana se desprende del propio mandato establecido en el artículo 10. constitucional, pues el principio pro persona obliga a los Jueces nacionales a resolver cada caso atendiendo a la interpretación más favorable a la persona. En cumplimiento de este mandato constitucional, los operadores jurídicos deben atender a lo siguiente: (i) cuando el criterio se haya emitido en un caso en el que el Estado Mexicano no haya sido parte, la aplicabilidad del precedente al caso específico debe determinarse con base en la verificación de la existencia de las mismas razones que motivaron el pronunciamiento; (ii) en todos los casos en que sea posible, debe armonizarse la jurisprudencia interamericana con la nacional; y (iii) de ser imposible la armonización, debe aplicarse el criterio que resulte más favorecedor para la protección de los derechos humanos." (SCJN:2014).

Derivado de la misma reforma constitucional, otros preceptos constitucionales concretamente los artículos 15, 103 y 105 incorporan en el mismo plano a los derechos humanos reconocidos en los tratados internacionales y en la Carta Magna, como parámetro de constitucionalidad para analizar la validez de los actos y normas jurídicas.

Los mencionados artículos disponen -en las partes conducentes- lo siguiente:

"Artículo 15. No se autoriza la celebración de tratados para la extradición de reos políticos, ni para la de aquellos delincuentes del orden común que hayan tenido en el país donde cometieron el delito, la condición de esclavos; ni de convenios o tratados en virtud de los que se alteren los derechos humanos reconocidos por esta Constitución y en los tratados internacionales de los que el Estado Mexicano sea parte.

Artículo 103. Los Tribunales de la Federación resolverán toda controversia que se suscite:

I. Por normas generales, actos u omisiones de la autoridad que violen los derechos humanos reconocidos y las garantías otorgadas para su protección por esta Constitución, así como por los tratados internacionales de los que el Estado Mexicano sea parte; ...

Artículo 105. La Suprema Corte de Justicia de la Nación conocerá, en los términos que señale la ley reglamentaria, de los asuntos siguientes:

I....

$\cdots$

II ....

$\ldots$

g) La Comisión Nacional de los Derechos Humanos, en contra de leyes de carácter federal, estatal y del Distrito Federal, así como de tratados internacionales celebrados por el Ejecutivo Federal y aprobados por el Senado de la República, que vulneren los derechos humanos consagrados en esta Constitución y en los tratados internacionales de los que 
México sea parte. Asimismo, los organismos de protección de los derechos humanos equivalentes en los estados de la República, en contra de leyes expedidas por las legislaturas locales y la Comisión de Derechos Humanos del Distrito Federal, en contra de leyes emitidas por la Asamblea Legislativa del Distrito Federal...."(CPEUM)

Como se advierte en los artículos 15 y 105 se utiliza la conjunción copulativa mientras que en el diverso artículo 103 se utiliza la conjunción comparativa "así como", lo que refleja la similitud entre ambos conjuntos de normas (SCJN, CDHDF: 2013).

La reforma a estos preceptos replantea la comprensión de los derechos humanos en México en muchos sentidos, pero en lo que se refiere a conformar un nuevo bloque de constitucionalidad, las modificaciones dan cuenta de una nueva realidad para los derechos humanos contenidos en los tratados internacionales al ubicarlos con la máxima jerarquía normativa dentro del texto constitucional.

Pese a estas consideraciones y a la gran trascendencia de la reforma de 2011, aún existen ciertas contradicciones en el texto constitucional mexicano, a propósito del principio de jerarquía normativa y la posición en la Constitución de los derechos humanos contenidos en tratados internacionales. En efecto, el diverso artículo 105 constitucional que al mes de septiembre de 2017 ha tenido doce reformas, establece que la Suprema Corte de Justicia de la Nación tiene la facultad para conocer de las acciones de inconstitucionalidad que tengan por objeto plantear la posible contradicción entre una norma de carácter general y la propia Constitución. En la fracción II de este precepto, se establecen varios supuestos para plantear dichas acciones de inconstitucionalidad, cuya finalidad es la anulación de una norma por contravenir al texto constitucional; entre dichos supuestos, el inciso b) de la fracción II señala que puede plantear la acción "El equivalente al treinta y tres por ciento de los integrantes del Senado, en contra de leyes federales o de tratados internacionales celebrados por el Estado Mexicano;" (CPEUM).

Esta disposición establece la hipótesis en la que la Constitución se ubica jerárquicamente por encima de los tratados internacionales (aún los de derechos humanos), al establecer que si existe una contradicción entre un tratado internacional celebrado por el Estado mexicano y la Constitución, el Senado puede plantear una acción de inconstitucionalidad a fin de que en su caso se declare la inconstitucionalidad y se anule su validez para el Derecho interno mexicano. De hecho, esta postura asumió inicialmente la Suprema Corte de Justicia de la Nación posterior a la reforma del año 2011 al sustentar el siguiente criterio:

"SUPREMACÍA CONSTITUCIONAL. LA REFORMA AL ARTÍCULO 1o. DE LA CONSTITUCIÓN POLÍTICA DE LOS ESTADOS UNIDOS MEXICANOS, DE 10 DE JUNIO DE 2011, RESPETA ESTE PRINCIPIO. La reforma al artículo 1o. de la Carta Magna, publicada el 10 de junio de 2011, en modo alguno contraviene el principio de supremacía constitucional consagrado desde 1917 en el artículo 133 del propio ordenamiento, que no ha sufrido reforma desde el 18 de enero de 1934, y en cuyo texto sigue determinando que "Esta Constitución, las leyes del Congreso de la Unión que emanen de ella y todos los Tratados que estén de acuerdo con la misma, celebrados y que se celebren 
por el Presidente de la República, con aprobación del Senado, serán la Ley Suprema de toda la Unión", lo cual implica que las leyes y los tratados internacionales se encuentran en un plano jerárquicamente inferior al de la Constitución, pues en el caso de las leyes claramente se establece que "de ella emanan" y en el de los tratados "que estén de acuerdo con la misma". Por otra parte, la reforma de 2011 no modificó los artículos 103, 105 y 107 constitucionales, en la parte en que permiten someter al control constitucional tanto el derecho interno, como los tratados internacionales, a través de la acción de inconstitucionalidad, la controversia constitucional y el juicio de amparo. Además, el propio artículo 1o. reformado dispone que en nuestro país todas las personas gozan de los derechos humanos reconocidos en la Constitución y en los tratados internacionales de los que México sea parte, pero categóricamente ordena que las limitaciones y restricciones a su ejercicio sólo pueden establecerse en la Constitución, no en los tratados; disposición que resulta acorde con el principio de supremacía constitucional. Principio que también es reconocido en el ámbito internacional, en el texto del artículo 46 de la Convención de Viena sobre el Derecho de los Tratados entre Estados y Organizaciones Internacionales, al prever la posibilidad de aducir como vicio en el consentimiento la existencia de una violación manifiesta que afecte a una norma de importancia fundamental de su derecho interno.

Amparo directo 30/2012. Gustavo Janett Zúñiga. 22 de agosto de 2012. Unanimidad de cuatro votos; votó con salvedades Sergio A. Valls Hernández. Ausente: José Fernando Franco González Salas. Ponente: Sergio Salvador Aguirre Anguiano. Secretaria: Erika Francesca Luce Carral.

Nota: Por ejecutoria del 9 de octubre de 2013, el Pleno declaró sin materia la contradicción de tesis 26/2013 derivada de la denuncia de la que fue objeto el criterio contenido en esta tesis, al existir las jurisprudencias P./J. 20/2014 (10a.) y P./J. 21/2014 (10a.) que resuelve el mismo problema jurídico." (SCJN: 2012).

Como la propia nota final del criterio refiere, en la tesis número P./J. 20/2014 (10a.), se matizó el anterior razonamiento para establecer que a raíz de la reforma constitucional de 2011, las normas de derechos humanos, al margen de la fuente que les dé origen, no se relacionan en términos jerárquicos y que en caso de que exista una restricción expresa al ejercicio de los derechos humanos, deberá prevalecer el contenido de la Constitución. Este criterio refiere lo siguiente:

\footnotetext{
"DERECHOS HUMANOS CONTENIDOS EN LA CONSTITUCIÓN Y EN LOS TRATADOS INTERNACIONALES. CONSTITUYEN EL PARÁMETRO DE CONTROL DE REGULARIDAD CONSTITUCIONAL, PERO CUANDO EN LA CONSTITUCIÓN HAYA UNA RESTRICCIÓN EXPRESA AL EJERCICIO DE AQUÉLLOS, SE DEBE ESTAR A LO QUE ESTABLECE EL TEXTO CONSTITUCIONAL. El primer párrafo del artículo 1o. constitucional reconoce un conjunto de derechos humanos cuyas fuentes son la Constitución y los tratados internacionales de los cuales el Estado Mexicano sea parte. De la interpretación literal, sistemática y originalista del contenido de las reformas constitucionales de seis y diez de junio de dos mil once, se desprende que las normas de derechos humanos, independientemente de su fuente, no se relacionan en términos jerárquicos, entendiendo que, derivado de la parte final del primer párrafo del citado artículo 1o., cuando en la Constitución haya una restricción expresa al ejercicio de los derechos humanos, se deberá estar a lo que indica la norma constitucional, ya que el principio que le brinda supremacía comporta el encumbramiento de la Constitución como norma fundamental del orden jurídico mexicano, lo que a su vez implica que el resto de las normas jurídicas deben ser acordes con la misma, tanto en un sentido formal como material, circunstancia que no ha cambiado; lo que sí ha evolucionado a raíz de las reformas constitucionales en comento es la
} 
configuración del conjunto de normas jurídicas respecto de las cuales puede predicarse dicha supremacía en el orden jurídico mexicano. Esta transformación se explica por la ampliación del catálogo de derechos humanos previsto dentro de la Constitución Política de los Estados Unidos Mexicanos, el cual evidentemente puede calificarse como parte del conjunto normativo que goza de esta supremacía constitucional. En este sentido, los derechos humanos, en su conjunto, constituyen el parámetro de control de regularidad constitucional, conforme al cual debe analizarse la validez de las normas y actos que forman parte del orden jurídico mexicano." (SCJN: 2014)

En ese sentido, se apunta que la posición jerárquica de la Constitución no se modificó con la citada reforma de 2011, ya que todas las demás reformas que integran parte del sistema jurídico mexicano, incluidos los tratados internacionales que México haya celebrado, deben estar acorde formal y materialmente con el texto constitucional. Sin embargo, el mismo criterio señala que lo que constituye un cambio trascendental con la reforma es el conjunto de normas con supremacía constitucional, dentro de las cuales se integra el catálogo de derechos humanos, que en conjunto, constituyen el parámetro de constitucionalidad de las demás normas del sistema jurídico mexicano.

Teniendo en cuenta lo anterior, es dable concluir que a partir de la reforma constitucional de 2011, las normas de derechos humanos contenidas en tratados internacionales celebrados por México, tienen supremacía constitucional y conforman, junto a las normas constitucionales de derechos humanos, el llamado bloque de constitucionalidad de los derechos humanos. Pero, la propia existencia de normas constitucionales que dan cuenta de la supremacía de la Constitución y la visión que de ello asume la Suprema Corte de Justicia de la Nación, plantea la hipótesis de que existe una suerte de normas constitucionales con diferente jerarquía normativa, pese a que se estipule la tesis de que las normas de derechos humanos no se relacionen en términos de jerarquía normativa. Esto es así, pues como se refiere en el anterior criterio, en caso de que exista una restricción expresa al ejercicio de los derechos humanos en la Constitución, se debe estar a lo que el propio texto constitucional dispone por encima de los tratados internacionales de derechos humanos.

De acuerdo a lo anterior, la Constitución mexicana teóricamente es rígida pues no sólo tiene una clara supremacía normativa que el resto del ordenamiento, sino que además, prevé un procedimiento especial o agravado para su modificación que no es llevado a cabo por el órgano legislativo ordinario, pues además de la votación calificada del Congreso de la Unión, se requiere de la aprobación de la mayoría de los parlamentos de los Estados.

No obstante lo anterior, si bien de acuerdo al propio texto normativo de la Constitución mexicana se la podría clasificar como una Constitución rígida y por lo tanto, podría asumirse que no suele reformarse con mucha frecuencia por el procedimiento de reforma, al mes de septiembre del presente año de 2017, la Constitución mexicana de 1917 que cumple 100 años de haber sido promulgada, cuenta ya con 706 reformas.

Se podría decir que es una Constitución rígida sumamente flexible, pues aunque el procedimiento para 
su reforma sea agravado o complejo desde el punto de vista teórico, lo cierto es que el número de reformas dan cuenta de lo habitual y ordinario que resulta realizar una modificación al texto constitucional.

Este reformismo o práctica de reformar constantemente a la Constitución mexicana ha tenido un auge en los últimos 40 años, pues es a partir de la década de los 70's a la fecha, cuando se han realizado prácticamente cerca del $80 \%$ de las reformas constitucionales, específicamente 567 a partir del sexenio de la presidencia de Luis Echeverría Álvarez.

Pero sin lugar a dudas, es el sexenio presidencial anterior de Felipe Calderón y el actual de Enrique Peña Nieto, los que han marcado la pauta de un hiper reformismo constitucional ya que entre ambos representan el 37\% de las reformas constitucionales. De manera concreta éstas han sido las reformas constitucionales desde 1976:

\section{LUIS ECHEVERRÍA ÁLVAREZ}

1o. de diciembre de 1970 al 30 de noviembre de 1976

971

972

974

975

976
Artículos 10, 73, 74 y 79

Artículos 52, 54, 55, 58 y 123 (1a. reforma, 2a. reforma)

Artículos 4o., 5o., 27, 30, 43, 45, 52, 55, 73, 74, 76, 79, 82, 89, 93, 104, 107 (1a. reforma, 2a. reforma), 111, 123 (1a. reforma, 2a. reforma) y 131

Artículos 27, 73, 107 y 123

Artículos 27 (1a. reforma, 2a. reforma), 73 y 115

40 artículos reformados

JOSÉ LÓPEZ PORTILLO Y PACHECO

1o. de diciembre de 1976 al 30 de noviembre de 1982

977

978

979

980
Artículos 6o., 18, 41, 51, 52, 53, 54, 55, 60, 61, 65, 70, 73, 74, 76, 93, 97 y 115

Artículo 123 (1a. reforma, 2a. reforma, 3a. reforma)

Artículo 107

Artículos 3o., 40. y 78

Artículos 29, 60, 90, 92 y 117 
981

982

Artículos 28, 73, 74 y 123

34 artículos reformados

MIGUEL DE LA MADRID HURTADO

1o. de diciembre de 1982 al 30 de noviembre de 1988

Artículos 20 y 79

Artículos 52, 53, 54, 56, 60, 65, 66, 69, 77, 106, 107 y 123

986

Artículo 89

66 artículos reformados reforma), 78, 79, 89, 94, 97, 101, 104, 107, 110, 111, 115, 116 y 127

Artículo Decimonoveno transitorio

\section{OS SALINAS DE GORTARI}

1o. de diciembre de 1988 al 30 de noviembre de 1994

Artículos 5o., 28, 35, 36, 41, 54, 60, 73 y 123

Artículos Decimoséptimo, Decimoctavo y Decimonoveno transitorios Artículos 3o., 4o., 5o., 24, 27 (1a. reforma, 2a. reforma), 102 y 130 reforma), 119 (1a. reforma, 2a. reforma), 122 y 123 
Artículos 21, 55, 73, 76, 79, 89, 93, 94, 95, 96, 97, 98, 99, 100, 101, 102, 103, 104, 105, 106, 107, $108,110,111,116,122$, y 123

995

Artículo 28

Artículos 16, 20, 21, 22, 35, 36, 41, 54, 56, 60, 73 (1a. reforma, 2 a. reforma), 74, 94, 98, 99, 101, 105, 108, 110, 111, 116 y 122

Artículos 30, 32 y 37

Artículos 4o., 16, 19, 22, 25, 58, 73 (1a. reforma, 2a. reforma, 3a. reforma), 74, 78, 79, 94, 97, 100, 102, 107, 115 y 123 Artículo Tercero transitorio del Decreto DOF 20-03-1997

Artículos 4o., 20 y 73

77 artículos reformados

\section{VICENTE FOX QUESADA}

$1^{\circ}$ de diciembre de 2000 al 30 de noviembre de 2006

001 Artículos 1o., 2o., 4o., 18 y 115

002 Artículos 3o., 31 y 113

003 Artículos 63, 73 y 77 Artículos 65, 73 (1a. reforma, 2a. reforma), 74 y 89

004 Artículo Segundo transitorio del Decreto DOF 20-03-1997

005 Artículos 14, 18, 21, 22, 46, 73 (1a. reforma, 2a. reforma), 76 y 105 Artículos 1o., 26, 73 (1a. reforma, 2a. reforma) y 105 31 artículos reformados

Felipe de Jesús Calderón Hinojosa

$1^{\circ}$ de diciembre de 2006 al 30 de noviembre de 2012

Artículos 6o. (1 a. reforma, 2a. reforma), 29, 41, 55, 73 (1a. reforma, 2a. reforma,3a. 

007 reforma), 76, 82, 85, 89, 90, 92, 93, 95, 97, 99 (1a. reforma, 2a. reforma),108, 110, 111, 116, 122 y 134 Artículos 16, 17, 18, 19, 20, 21, 22, 69, 73 (1a. reforma, 2a. reforma), 74, 79, 88,93, 115, 116 (1a.
008 reforma, 2a. reforma), 122, 123 y 134
Artículos 4, 16 (fe de errata), 73 (1a. reforma, 2a. reforma, 3a. reforma)
009 Artículos Segundo y Tercero transitorios del Decreto DOF 12-12-2005 Artículos 75, 115, 116, 122, 123 y 127
010 Artículos 17 y 122
Artículos 1o., 3o., 4o. (1a. reforma, 2a. reforma, 3a.
011 reforma), 11, 15, 18, 19, 20,27, 29, 33, 43, 71, 72, 73 (1a. reforma, 2a. reforma, 3a. reforma), 78, 89, 94, 97,102, 103, 104, 105 y 107 Artículos 3o., 4o., 31, 35, 36, 40, 46, 71, 73 (1 a. reforma, 2a. reforma), 74, 76, (1 a. reforma, 2a. reforma), $78,83,84,85,87,89,105,116$ y 122

110 artículos reformados

Enrique Peña Nieto

$1^{\circ}$ de diciembre de 2012 al 30 de noviembre de 2017

Artículos 3o., 6o., 7o., 24, 25 (1a. reforma, 2a. reforma), 26, 27 (1a. reforma, 2a. reforma), 28 (1a. 013 reforma, 2a. reforma), 37,73 (1a. reforma, 2a. reforma, 3a. reforma, 4a. reforma), 78, 94, 105, 116 y 122 Artículos 4o., 6o., 26, 28, 29, 35, 41 (1a. reforma, 2a. reforma), 54, 55, 59, 65,69, 73 (1a. reforma, 2a. reforma), 74, 76 (1a. reforma, 2a. reforma), 78, 82, 83,84, 89 (1a. reforma, 2a. reforma), 90, 93, 95, 99, 102, 105 (1a. reforma, 2a. reforma), 107, 108 (1a. reforma, 2a. reforma), 110 (1a. reforma, 2a. reforma), 111 (1a. reforma, 2a. reforma), 115, 116 (1a. reforma, 2a. reforma), 119, 122 (1a. reforma, 2a. reforma) y 123

Artículos 2o., 18, 22, 25, 28, 41,73 (1a. reforma, 2a. reforma, 3a. reforma, 4a. reforma), 74, 76, 79 (1a. reforma, 2a. reforma), 104, 108 (1a. reforma, 2a. reforma), 109, 113, 114, 116 (1a. reforma, 2a. reforma), 117 y 122

Artículos 2o., 3o., 5o., 6o., 11, 17, 18, 21, 26 (1a. reforma, 2a. reforma), 27, 28,31, 36, 40, 41 (1a. reforma, 2a. reforma), 43, 44, 53, 55, 56, 62, 71, 73 (1a. reforma, 2a.

016 reforma), 76, 79, 82, 89, 95, 101, 102, 103, 104, 105, 106, 107, 108,110, 111,115, 117, 119, 120, 121, 122, 123 (1a. reforma, 2a. reforma), 124, 125,127, 130, 131, 133, 134 y 135 017 Artículos 16, 17, 25, 73 (1ª reforma, 2a reforma), 107 y 123 | Nueva reforma |

154 artículos reformados al 15 de septiembre de 2017 (DIPUTADOS: 2017)

El contexto de reformismo constitucional mexicano ha dado pie a una obesidad del texto de la Constitución, de hecho, se podría afirmar válidamente que la Carta Magna promulgada en 1917 poco se parece al texto vigente, pues los 706 cambios que ha tenido, han supuesto un aumento desmesurado de sus contenidos. En efecto, no sólo se han modificado los contenidos del texto constitucional bajo el argumento de que la 
Constitución debe adaptarse a la realidad mexicana, sino que además, la realidad mexicana fundada en la desconfianza ha dado pie a un evidente afán reglamentista para ubicar un gran cúmulo de preceptos sumamente detallados dentro del texto constitucional.

Lo que en todo caso queda de manifiesto, es que ese reformismo constitucional ha trastocado casi todo el contenido de la Carta Magna. Como refiere Diego Valadés (para el año 2013), de los 136 artículos de la Constitución mexicana, sólo 22 no habían sido modificados, es decir, sólo el 16\% permanecía intocado y como se afirma, si de hecho se midiera qué porcentaje del texto actual es lo que queda del texto original de 1917, sería sólo el 3\% (VALADÉS: 2013: 23). En ese orden de ideas, al día de hoy la Constitución mexicana no únicamente ha tenido y sigue teniendo cambios que distan mucho de su texto original, sino que tiene un problema de obesidad pues como refiere Héctor Fix-Fierro, el texto original de 1917 tenía aproximadamente 21 mil palabras, mientras que a la fecha tiene más de 66 mil (FIX-FIERRO: 2017: 147), lo que supone un aumento del triple de su extensión original.

Buena muestra de ese crecimiento desmedido y de la enorme vocación reglamentaria de situar contenidos sumamente detallados en la Constitución es el artículo 41, el cual establece las bases normativas del Instituto Nacional Electoral, de los partidos políticos y de los procesos electorales; este precepto que originalmente tenía 63 palabras, hoy en día tiene casi 3 mil, unas 45 veces más extenso (FIX-FIERRO: 2017: 147).

\section{ESTADO DE DERECHO Y CULTURA CONSTITUCIONAL}

Esta obesidad reglamentaria y reformismo constitucional mexicanos bien podrían justificarse si la Constitución mexicana reflejara a un Estado de Derecho en la que el conocimiento y la observancia de los preceptos constitucionales fueran una realidad cotidiana, sin embargo, el escenario actual da cuenta de todo lo contrario, en donde es la ilegalidad y una débil cultura constitucional lo que prevalece en el país ${ }^{2}$ (ANSUÁTEGUI: 2006: 190).

México, como muchos Estados democráticos enfrentan una crisis de legalidad expresada en la ausencia o ineficacia de los controles, como lo denomina Ferrajoli la "variada y llamativa fenomenología de la ilegalidad del poder"(FERRAJOLI: 1999: 15).

La ilegalidad del poder o sistema de corrupción asociada a la débil cultura de legalidad que ya se ha apuntado, ha degradado las reglas del juego institucional generando una práctica de la impunidad que en el caso

\footnotetext{
${ }^{2}$ Si bien como refiere el profesor Ansuátegui los derechos fundamentales son el núcleo del Estado de Derecho desde una perspectiva material, lo cierto es que en el caso mexicano no se ha podido consolidar al Estado de Derecho desde una perspectiva formal, es decir, el sometimiento del Poder al Derecho como una condición básica.
} 
de México, aunado a factores históricos, culturales y coyunturales, han agravado la crisis de seguridad pública, al grado de ser uno de los problemas más graves para el Estado mexicano. En esa tesitura, las 706 reformas a la Constitución y el aumento de sus contenidos no han podido empujar a la realidad del país y mitigar esa crisis de inseguridad pública.

La crisis de seguridad pública obedece a muchos factores, pero en las cifras de homicidios dolosos es donde puede advertirse la gravedad del problema que atraviesa México desde hace algunos años. Después de la transición política del año 2000, y de enero de 2001 a agosto de 2007, hubo una disminución gradual en la tasa mensual del delito de homicidio doloso pasando de 1.2 a 0.72 homicidios por cada 100 mil habitantes; sin embargo, en el sexenio del ex Presidente Felipe Calderón, particularmente después del inicio de la llamada "guerra contra el narcotráfico", de enero de 2008 a mayo de 2011, esa cifra aumentó a 1.86 homicidios dolosos por cada 100 mil habitantes. Por otro lado, pese a que durante la primera parte del sexenio del Presidente Peña Nieto hubo una disminución de esta cifra pues de finales del año 2012 a febrero de 2015 la cifra disminuyó a 1.05, a partir de marzo de este año a agosto de 2016 la cifra aumentó a 1.59 homicidios dolosos por cada 100 mil habitantes (MÉXICO EVALÚA: 2017: 32).

De hecho, según cifras del Secretariado Ejecutivo del Sistema Nacional de Seguridad Pública entre diciembre de 2006 y octubre de 2012 se registraron un total de 101 mil 199 denuncias de homicidio doloso, cifra que representó un aumento del 35.7\% respecto al sexenio anterior (MÉXICO: EVALÚA: 2012: 43). Esta cifra contrasta con los datos del Instituto Nacional de Estadística y Geografía, según los cuales de diciembre del 2006 a diciembre de 2010, se registraron 69 mil 282 muertes por homicidio, de las cuales 34 mil 612 tuvieron relación con presunta rivalidad delicuencial (MÉXICO: EVALÚA: 2012: 51). El contraste de estas cifras y el contexto real de inseguridad pública que se vive en el país, hace que sea complejo establecer con plena certeza la cifra de homicidios vinculados a la guerra contra el narcotráfico en el periodo de los años del 2006 al 2012, sin embargo, existen datos no oficiales que aseveran que se registraron muchos más homicidios relacionados con el crimen organizado ${ }^{3}$.

En el sexenio de Gobierno de 2012-2018 las cifras de muertes por homicidios dolosos y las relacionadas con el crimen organizado no son alentadoras. Pese a que resulta difícil establecer con plena certeza el número de homicidios dolosos teniendo en cuenta el número de denuncias sobre desaparición de personas, según cifras no oficiales, la tendencia sería parecida al sexenio anterior pues el número de esas muertes estaría cercano o superior a

\footnotetext{
${ }^{3}$ Cifras no oficiales que refieren más de 100 mil las muertes relacionadas con el crimen organizado, contabilizados desde el año del 2006 al 2012. Vid. Periódico La Jornada en línea. Disponible en: http://www.jornada.unam.mx/2012/12/11/politica/015n1pol; Revista Proceso Disponible en: http://www.proceso.com.mx/348816/mas-de-121-mil-muertos-el-saldo-de-la-narcoguerra-decalderon-inegi, fecha de consulta: 15 de diciembre de 2017.
} 
las 100 mil personas 4 .

Pese a la falta de certeza plena sobre las cifras reales de muertes violentas en el país, lo cierto es que existe una grave crisis de violencia pues algunos organismos como el International Institute for Strategic Studies, refieren que México es el país donde más personas murieron de forma violenta en el año 2016 sólo por detrás de Siria y por encima de países con conflictos bélicos como Irak o Afganistán (BBC MUNDO: 2017).

En este sentido, organizaciones de la sociedad civil reconocidas como Human rights watch, coinciden en que en los últimos años, en México se ha dado un incremento alarmante en los homicidios relacionados con organizaciones delictivas que compiten por el control del narcotráfico y otras actividades ilícitas lucrativas; esto, va ligado a otros problemas como la impunidad de abusos militares; un sistema penal ordinario que no ofrece justicia a las víctimas de crímenes violentos y violaciones de derechos humanos; ataques a la libertad de expresión, especialmente a periodistas que realizan investigaciones relacionas con el crimen organizado; así como, la persecución de defensores de derechos humanos, entre otros problemas que reflejan una crisis importante de los derechos humanos en el país, derivado de problemática compleja que representa el crimen organizado (WORLD REPORT: 2011).

Este contexto de inseguridad pública que vive México pone de manifiesto la fragilidad del Estado para garantizar la seguridad pública en el país, que sin duda es una de las funciones básicas del Estado, pues eso constituye el cimiento de la protección y el disfrute de los derechos fundamentales y del ordenamiento constitucional; en el extremo, la grave crisis de inseguridad pública que vive el país no sólo es uno de los retos más importantes del Estado y la sociedad actual, sino que además, acentúa las carencias históricas en otros ámbitos que son básicos para el bienestar de las personas. Las cifras de organismos reconocidos revelan que se necesitan medidas urgentes para revertir la crisis que atraviesan los derechos fundamentales en México, que sin duda son la piedra angular de la Constitución y criterio de legitimidad del Estado.

Estos datos reflejan la crisis de inseguridad pública y de ilegalidad que vive México, los cuales dan cuenta de la falta de efectividad del texto constitucional, en buena medida por la ausencia de una cultura sólida en la sociedad que practique y conozca los contenidos de la Carta Magna.

En el año 2003, 2011 y 2016 el Instituto de Investigaciones Jurídicas de la Universidad Nacional Autónoma de México, realizó las encuestas nacionales de cultura constitucional, en los temas de legalidad, legitimidad de las instituciones y rediseño del Estado, elaboradas por especialistas de dicho instituto con el

\footnotetext{
4 Periódico el Universal. Disponible en: http://www.eluniversal.com.mx/entrada-de-opinion/columna/alejandrohope/nacion/2017/07/28/los-117-mil-muertos-de-pena-nieto; Aristegui Noticias. Disponible en: https://aristeguinoticias.com/2401/mexico/con-epn-mas-ejecutados-que-en-todo-el-sexenio-de-calderon/, fecha de consulta: 15 de diciembre de 2017.
} 
propósito de generar una línea base de información que permitiera dar cuenta de la extensión y modalidades del diseño institucional en la sociedad mexicana, fundamentalmente, para conocer los factores principales que inciden en las actitudes, opiniones y valores de la población frente a la Constitución, la legalidad y la justicia (ECC: 2011).

En la primera encuesta se hicieron entrevistas a 1794 personas mayores de 15 años, la mitad mujeres y la mitad hombres, mientras que en el 2011 se aplicaron 2208 cuestionarios generales de opinión en vivienda en una muestra a nivel nacional.

Los datos que arrojaron las citadas encuestas de 2003 y 2011 dan cuenta que no existía confianza en los gobernantes ni en las instituciones públicas del país, pero también reflejan algunas visiones autoritarias de los ciudadanos y aunque pareciera que existe una mediana concepción de la justicia, hay un desconocimiento generalizado de la Constitución y las leyes, lo que sin duda, dificulta la construcción de una cultura constitucional, de legalidad y de respeto a los derechos humanos.

En la encuesta de 2011, inicialmente, puede apuntarse que sólo la mitad de los entrevistados se interesa en los asuntos públicos del país, mientras que la otra mitad se interesa poco; de esta mitad, un 18.9\% expresaron que no se interesaba nada en los asunto públicos del país, que constituyen al grupo de personas entre 25 y 29 años y quienes tienen más de 60 años, personas con bajos ingresos, y que no se identifican con ningún partido político (ECC: 2011).

Por otro lado, del 2003 al 201 1, aumentó del 38.8\% al 49\% el porcentaje de los entrevistados a los que no les interesan los asuntos que se discuten en el parlamento del país. De acuerdo a estos datos, son los jóvenes entre los 15 y 29 años los que se interesan menos (ECC: 2011).

La falta de interés en los asuntos públicos del país, incluidos los asuntos que se tratan en el parlamento de al menos la mitad de la población según esta encuesta de 2011, da cuenta de la dificultad de construir una cultura constitucional y de legalidad en México, si de entrada no existe la intención de conocer los asuntos públicos. En síntesis, no es posible construir con éxito una cultura de legalidad si no existe una ciudadanía participativa.

Seguramente por la crisis de violencia que ha vivido el país desde hace algunos años, la mayoría de los ciudadanos elige a su seguridad frente a la libertad, si tuviera que escoger entre alguno de esos valores. Así, cuatro de cada diez entrevistados elige a la seguridad frente a la libertad, mientras que poco más de tres de cada diez entrevistados elige a la libertad. Sólo dos de cada diez escogieron espontáneamente ambos (ECC: 2011).

Existe en la mayoría de los encuestados una visión de que es la familia la que debe poner los límites a la conducta a las personas, seguida de la ley, y uno mismo, mientras que en cuarto sitio está el Gobierno. Según estos datos, el 34.3\% de los entrevistados considera que debe ser la familia la que ponga esos límites, el 26.3\% que sea la 
ley, el 16.2\% que sea uno mismo, el 13.7\% que sea el Gobierno, el 6.6\% que sea la Iglesia, y el resto consideró que otros, nadie o no sabe (ECC: 2011).

La mayoría de los entrevistados (apenas más de la mitad) considera que el pueblo debe obedecer y cumplir siempre las leyes porque nos beneficia a todos. Así pues, en la encuesta de 2011, el 52.9\% de los entrevistados considera que el pueblo debe obedecer siempre las leyes y sólo una proporción menor, el 18.9\%, cree que el pueblo debe desobedecerlas si le parecen injustas. Asimismo, el $49.5 \%$ respeta y obedece las leyes porque nos beneficia a todos. En este caso, tanto en 2003 como en 2011, la segunda opción en importancia es que hay que obedecer la ley porque es un deber moral (25\% de los entrevistados). Es decir, la mayoría de los entrevistados considera que el obedecer a las leyes es positivo por un beneficio colectivo, mientras que una cuarta parte de los entrevistados considera que se deben cumplir las normas por un deber moral (ECC: 2011).

La proporción de entrevistados que considera que se debe cumplir con la ley, no es lejana a la percepción que la gente tiene sobre qué tanto cree que se respetan las leyes por los demás, aunque en promedio, la gente dice respetar las leyes más de lo que los demás la cumplen. Así, en una escala de 0 a 10, donde 0 es no respeta nada y 10 es respeta mucho, 7.84 considera que respeta la ley, mientras 5.65 cree que se respetan las leyes en México (ECC: 2011).

Según la encuesta de 2011, la percepción de los entrevistados sobre el cumplimiento de la ley en México tiene relación directa con tres aspectos centrales sobre la Constitución, por una parte, la mayoría de los entrevistados considera que la carta magna ya no responde a las necesidades del país, que por otro lado, debe modificarse toda o en parte y sobre todo, que una gran mayoría conoce poco o nada a su Constitución. Así, de los entrevistados, sólo el 27.8\% considera que nuestra Constitución responde a las necesidades del país, mientras que el 56\% considera que ya no responde a las necesidades. Por otra parte, en 2011, el 68.7\% de los entrevistados, consideraba que la Constitución debe cambiarse en parte (el 50.1\%) o hacer una nueva (el 18.6\%). Por último, un dato que es sumamente preocupante para la construcción de una cultura constitucional, es que de los entrevistados, el $65.1 \%$ respondió que conoce poco a la Constitución, mientras que el 27.7\% respondió que no conoce nada de su Constitución (ECC: 2011).

Los anteriores datos corresponden a la primera y segunda encuesta nacional de cultura de legalidad de los años 2003 y 2011 , en las que se da cuenta de un panorama desalentador en el interés y el conocimiento de la sociedad mexicana en relación con sus derechos y obligaciones, las instituciones, la autoridad y los asuntos de interés nacional.

En la tercera encuesta de cultura constitucional del 2016 se entrevistaron a 1200 personas mayores de 15 años en todo el país (ECC: 2017). Los datos que arroja esta última encuesta reflejan un creciente malestar, 
desconocimiento y desinterés en la sociedad mexicana en relación a aquellos temas antes apuntados que dan viabilidad a conceptos como democracia, Constitución, derechos humanos, y justicia, entre otros.

Los datos de la tercera encuesta de cultura constitucional reflejan que no existe un conocimiento generalizado y puntual del contexto y de la importancia histórica de la Constitución mexicana, ya que de los entrevistados solamente el $24 \%$ respondió que el texto constitucional nació a partir de la revolución mexicana de 1910, mientras que el 34.9\% respondió que nació a partir de la independencia de México, el 23.1\% no supo, el 11.4\% en la Guerra de Reforma y el 3.9\% en el movimiento estudiantil de 1968 (ECC: 2017).

Por otro lado, no obstante que la Constitución mexicana es la primera en haber reconocido derechos sociales y que sus contenidos marcaron un antes y después en la historia de la educación mexicana, así como las leyes laborales y agraria, lo cierto es que la gran mayoría de la sociedad no conoce la trascendencia de estas cuestiones. Así, ante la pregunta de cuál fue la aportación de la Constitución de 1917 para el mundo, el 62\% de los entrevistados no supo o no contestó la pregunta, el 7.8\% contestó que los derechos políticos, el $6.3 \%$ el orden y respeto, el 6.0\% las leyes, el $4.5 \%$ las garantías individuales, el 3.8\% la soberanía, el $3.5 \%$ la igualdad, el $2.6 \%$ los derechos sociales de trabajadores y campesinos, el 2.4\% los valores y el 1.1\% menciones dispersas (ECC: 2017).

Otro dato sumamente contrastante que denota la percepción de la sociedad ajena a la Constitución es el que da cuenta a la pregunta de qué tanto se reforma la Constitución. En ella, sólo el 12\% de los entrevistados dijo que con mucha frecuencia, mientras que el $23.4 \%$ contestó que con alguna frecuencia, el $31 \%$ contestó que con poca frecuencia, el $8 \%$ dijo que no se reformaba y el 22\% que no sabía (ECC: 2017). Como se dijo antes, el texto de la Constitución además de haberse reformado 706 veces, ha aumentado el triple en su extensión, lo que sin duda es un factor importante para la comprensión y el conocimiento generalizado de la Constitución, cuestión que queda de manifiesto en la tercera encuesta de cultura constitucional. En efecto, a la pregunta de qué tanto considera usted que conoce a la Constitución: ¿̇mucho, poco o nada?, solamente el 4.9\% de los encuestados contestó que mucho, el $56.1 \%$ contestó que poco, mientras que el $34.4 \%$ contestó que nada (ECC: 2017).

Algunas organizaciones de la sociedad civil en México han abordado también la percepción de los ciudadanos en relación a las leyes bajo la premisa de tener un diagnóstico de la cultura de legalidad en México. La Asociación Civil México Unido contra la delincuencia, promovió el desarrollo de un instrumento denominado "Índice de Cultura de Legalidad en México" para conocer el respeto a la ley en el país. Este instrumento tuvo como base una encuesta realizada por Consulta Mitofsky entre el 30 de mayo y el 08 de junio del 2014 a partir de 2,500 casos (MITOFSKY: 2017).

El índice en mención se compone de tres ejes:

“1. Valoración y/o Aprecio de la Cultura de la Legalidad. Construido por variables que evalúan la forma 
en la que los encuestados declaran que el respeto, conocimiento y cumplimiento de las leyes y prácticas cívicas es importante para una mejor vida en sociedad.

2. Percepción de la Cultura de la Legalidad en los otros. Construido con variables que evalúan la percepción de los encuestados sobre formas de respeto, conocimiento y cumplimiento de las leyes y prácticas cívicas en su entorno, concretamente en los otros.

3. Prácticas de la Cultura de la Legalidad en la persona. Construido con variables que dan elementos para conocer si los encuestados declaran tener respeto, conocimiento y cumplimiento de las leyes y prácticas cívicas" (CL: 2017).

A partir de estos ejes, el Índice de Cultura de la Legalidad (ICL) refleja que en general la población mexicana reprueba al obtener un ICL de 5.5 sobre 10. Según estos datos, el valor y aprecio de los mexicanos por la legalidad es de un 6.9, sin embargo, la conducta cívica y legal es de un 3.2; por otro lado, se pudo apreciar que los jóvenes entre 18 y 19 años con estudios universitarios, además de los trabajadores formales, son quienes más alto ICL presentan, obteniendo un 5.8 en ambos casos. En cuanto a la edad, las personas de 50 años o más, son quienes obtuvieron la calificación más baja con un 5.4 .

Respecto al rango de edad, los datos de este instrumento reflejan que los hombres jóvenes de entre $18 \mathrm{y}$ 29 años son quienes mejor evaluados resultan en ese rubro, con 3.4, mientras que son las personas mayores de 50 años las que menos prácticas pro cultura de la legalidad declaran, con 2.8. Esta tendencia permanece cuando, además de la edad, se hace una división por género; hombres y mujeres mayores de 50 años reconocen menos prácticas de cultura de la legalidad. La evaluación indica 3.0 en ellos por 2.6 en ellas (PICL: 2017).

De lo antes expuesto, resulta preocupante el contexto para la construcción de una cultura de legalidad en la que los derechos fundamentales sean una práctica constante y generalizada. Así pues, la efectividad de los derechos va de la mano con la cultura de legalidad y política pues "no son sino significados normativos, cuya percepción y aceptación social como vinculantes es la primera, in dispensable condición de su efectividad".

El nexo entre Constitución, derechos fundamentales y cultura resulta central. Aquella debe entenderse no sólo como ordenamiento jurídico dirigido a los abogados que deben interpretarla conforme a las reglas de la profesión, sino además, la Constitución, en cuanto cultura, debe actuar como una guía para los ciudadanos no juristas, debe ser expresión de un estadío cultural, medio para la representación del pueblo ante sí mismo, espejo de su patrimonio cultural y fundamento de sus esperanzas (HABERLE: 2003: 5).. En esta lógica, la Constitución debería poder institucionalizar el principio de la esperanza de un pueblo, representar el pacto de todos de los ciudadanos sobre el futuro posible y deseable común, constituyendo por lo menos "deseos de utopía" concretos (FERRAJOLI: 1999: 68). 
El gran aumento de contenidos reglamentarios y la reforma constante de la Constitución mexicana no facilitan una consolidación de una cultura constitucional generalizada, centralmente porque su contenido es de difícil comprensión para quienes no son especialistas en la materia.

Aún perfeccionando los mecanismos jurídicos para la defensa de la carta magna mexicana, "una Constitución solamente puede ser protegida politicamente o en la profundidad cultural (...) cuando todos poseen una voluntad de Constitución y esta desenvuelve duramente su fuerza normativa"(HABERLE: 2003: 5).

En palabras de Elías Díaz "la promulgación/vigencia es la señal de existencia de la norma, la base del Derecho como normatividad. Respetar la ley significa acatarla, obedecerla, cumplirla. La evasiva tradicional <se acata pero no se cumple> no es más que una astuta añagaza o pretexto formalista para en realidad no respetar, ni tampoco acatar la ley."(DÍAZ: 2013: 48)

\section{CONCLUSIONES}

Si bien la Constitución mexicana tiene un diseño de reforma rígido, en los hechos ha sido sumamente flexible lo que ha hecho que a cien años de su aprobación se hayan promulgado más de setecientas reformas. Estas modificaciones han modificado sustancialmente los contenidos de la carta magna pero además, han aumentado casi al triple su tamaño lo que la ha vuelto un texto normativo complejo para su comprensión.

El constante cambio del texto constitucional aunado a la compleja estructura de su contenido, junto a otros factores sociales, políticos y culturales, han propiciado una débil cultura constitucional y de legalidad que progresivamente han hecho más grande la brecha entre la visión y las prácticas de los ciudadanos mexicanos en relación con su Constitución y con los valores y principios propios de una sociedad democrática.

No se puede articular la construcción de un Estado de Derecho en sentido formal o material si no se tiene una base cultural más o menos sólida y generalizada, de ahí que el número de reformas constitucionales y la sola producción legislativa no basten para la vigencia efectiva y real del texto constitucional.

La praxis reiterada de modificar constantemente la Constitución introduciendo contenidos propios de cada administración pública, sobre todo de particularidades propias de una legislación reglamentaria, dan cuenta de la desconfianza generalizada de la clase política y de la pretendida certeza que puede brindar el texto constitucional, lo que parece haber sido una constante que se agrava progresivamente.

Una débil o nula cultura constitucional y de legalidad se suman a la grave crisis de violencia y de derechos humanos que vive México, lo que pone de manifiesto la necesidad de replantear la forma en que el poder público y la sociedad se relacionan con su Constitución. No se puede construir una cultura constitucional generalizada si de 
inicio su contenido es sumamente complejo y cambiante, de ahí que hoy sea necesario reflexionar sobre la necesidad de un nuevo texto constitucional, acompañado de una nueva forma de concebir a la Constitución, no sólo como una norma jurídica creada para los operadores jurídicos, sino además como cultura, como conjunto de hábitos, costumbres, valores y principios que sean la base de una sociedad y soporte del Estado democrático de Derecho.

\title{
REFLECTIONS ON REFORMISM AND CONSTITUTIONAL OBESITY IN MEXICO. FROM THE INSTITUTIONAL CUSTOM TO CULTURAL REALITY
}

\begin{abstract}
The paper intends to analyze the multiple reforms to the Mexican Constitution that reflect an excessive reformist activity of the legislators, as well as the great increase of the content

of the Constitution since its approval in the year 1917. The enormous increase of its contents as well as the constant reform of the Constitution has not been reflected in a culture of legality, on the contrary, at present there is a general ignorance of the Mexican constitutional text, in addition to serious problems in the country that pose a crisis of the State, the Constitution and human rights. This brief contribution aims to show that reformism and the excessive increase of the contents of the Mexican Constitution are not the proper way to consolidate the Mexican State of Law.
\end{abstract}

Keywords: Reformism, Mexican constitution, constitutional culture, rule of law, constitutional rigidity.

\section{FUENTES DE LA INVESTIGACIÓN}

AA.VV. Cada víctima cuenta: hacia un sistema de información delictiva confiable, México Evalúa, Centro de Análisis de Políticas Públicas, México, 2017.

Los mexicanos y su constitución. Tercera encuesta de cultura constitucional. Centenario de la Constitución de 1917., UNAM, Instituto de Investigaciones Jurídicas, México, 2017. 
ANSUÁTEGUI ROIG, Francisco Javier, "La relación entre los derechos fundamentales y el Estado de Derecho: dimensiones y consecuencias.", en Anuario de Filosofia del Derecho, No. 23, España, 2006.

Aristegui

Noticias.

Disponible

en:

https://aristeguinoticias.com/2401/mexico/conepnmasejecutadosqueentodoelsexeniodecalderon/, fecha de consulta: 15 de diciembre de 2017.

Bloque de constitucionalidad en México, Suprema Corte de Justicia de la Nación, Oficina en México del Alto Comisionado de las Naciones Unidas para los Derechos Humanos y Comisión de Derechos Humanos del Distrito Federal, México, 2013.

CARPIZO, Jorge, La Constitución Mexicana de 1917, Tercera edición, Instituto de Investigaciones Jurídicas, Universidad Nacional Autónoma de México, México, 1979.

Constitución Política de los Estado Unidos Mexicanos. Disponible en: http://www.diputados.gob.mx/LeyesBiblio/pdf/1_150917.pdf, fecha de consulta: 06 de mayo de 2017.

Consulta Mitofsky. Disponible en: http://consulta.mx/, fecha de consulta: 16 de octubre de 2017.

Cultura de la Legalidad. Disponible en: http://www.culturadelalegalidad.org.mx/ \%C3\%8DndiceCulturadelaLegalidadc1205i0.html\#, fecha de consulta: 16 de octubre de 2017.

DÍAZ, Elías, El derecho y el poder. Realismo crítico y filosofia del derecho,, Dykinson, Madrid, 2013.

Encuesta Nacional de Cultura Constitucional: legalidad, legitimidad de las instituciones y rediseño del Estado. IFEIIJ, 2011. UNAM, Disponible en: http://www.juridicas.unam.mx/invest/areas/opinion/EncuestaConstitucion/resultados.htm, fecha de consulta: 15 de agosto de 2017.

FERRAJOLI, Luigi, "Derechos y garantías. La ley del más débil, Ed. Trotta, Madrid, 1999. 
FIXFIERRO, Héctor, “¿Por qué se reforma tanto la Constitución mexicana de 1917? Hacia la renovación del texto y la cultura de la Constitución.", en Cien ensayos para el centenario. Constitución Política de los Estados Unidos Mexicanos, tomo4: Estudios Políticos, UNAM, Instituto de Investigaciones Jurídicas, México, 2017.

GUASTINI, Riccardo, "Rigidez constitucional y límites a la reforma en el ordenamiento italiano", en Revista Anuario del Departamento de Derecho de la Universidad Iberoamericana, Número 30, 2000.

HABERLE, Peter, El Estado Constitucional, Universidad Nacional Autónoma de México, México, 2003.

Noticias BBC Mundo. Disponible en: http://www.bbc.com/mundo/noticiasamericalatina39877442, fecha de consulta: 15 de diciembre de 2017.

Original: Constitución Política de los Estados Unidos Mexicanos. DOF 05021917. Disponible en: http://www.diputados.gob.mx/LeyesBiblio/ref/cpeum/CPEUM_orig_ 05feb1917.pdf, fecha de consulta: fecha de consulta: 11 de mayo de 2017.

Periódico

El

Universal.

Disponible

en:

http://www.eluniversal.com.mx/entradadeopinion/columna/alejandrohope/nacion/2017/07/28/los117milm uertosdepenanieto, fecha de consulta: 15 de diciembre de 2017.

Periódico La Jornada en línea. Disponible en: http://www.jornada.unam.mx/2012/12/11/politica/015n1pol, fecha de consulta: 15 de diciembre de 2017.

Primer índice de cultura de la legalidad en México. Disponible en: http://www.culturadelalegalidad.org.mx/recursos/Contenidos/ndiceCulturadelaLegalidad/otrosarchivos/pre2. pdf, fecha de consulta: 16 de octubre de 2017.

Reformas constitucionales por artículo. Disponible http://www.diputados.gob.mx/LeyesBiblio/ref/cpeum_art.htm, fecha de consulta: fecha de consulta: 18 de junio de 2017. 
Reformas Constitucionales por Periodo Presidencial. Disponible en: http://www.diputados.gob.mx/LeyesBiblio/ref/cpeum_per.htm, fecha de consulta: fecha de consulta: 20 de octubre de 2017.

Revista Proceso Disponible en: http://www.proceso.com.mx/348816/masde121milmuertoselsaldodelanarcoguerradecalderoninegi, fecha de consulta: 15 de diciembre de 2017.

Tesis 2a. LXXV/2012, Semanario Judicial de la Federación y su Gaceta, Novena Época, Libro XIII, Tomo 3, octubre de 2012, p. 2038.

Tesis P./J.21/2014 (10a.) Semanario Judicial de la Federación, Decima Época, Libro 5, Tomo I, abril de 2014, p. 204.

VALADÉS, Diego, "La Constitución reformadora”, en El constitucionalismo contemporáneo. Homenaje a Jorge Carpizo, UNAM, México, 2013.

World report 2011. Capítulo del Informe Mundial: México. Human Rigths Watch. Disponible en: http://www.hrw.org/es/worldreport2012/mxico, fecha de consulta: 17 de diciembre de 2017.

Trabalho enviado em 17 de setembro de 2018

Aceito em 03 de novembro de 2018 